GÖRAN SUNDHOLM

\title{
ONTOLOGIC VERSUS EPISTEMOLOGIC: SOME STRANDS IN THE DEVELOPMENT OF LOGIC,
} 1837-1957*

Traditionally the subject matter of logic comprised judgements and inferences, that is, the products of certain (mental) acts. Indeed, Thomas Aquinas even characterized logic as the study of terms in 'the second intention', that is, such terms that themselves have mental entities as their intention, examples being the term 'term', the term 'judgement' and the term 'inference'. Today, on the other hand, authoritative elementary text books in Logic make no mention of products of mental acts: the acting logical subject that has to draw the inferences in question has, as it were, been squeezed out of the province of logic.

Inferences, that is, acts of passage in which a certain judgement, the conclusion of the inference, is drawn on the basis of certain already made judgements, the premisses of the inference, have yielded their central place at the hard core of logic to relations of logical consequence between propositions that serve as contents of the judgements involved, or even more commonly, between well-formed formulae, that is, between meta-mathematical objects of an uninterpreted formal language. In the present paper I intend to review some of the steps in the process whereby this came about, as well as mention a couple of philosophical corollaries.

Quine, in 1952, held that 'logic is an old subject and since 1879 it has been a great one'. ${ }^{1}$ No one reasonably informed concerning the

\footnotetext{
* This paper develops a theme that was first adumbrated in my inaugural lecture Oordeel en Gevolgtrekking. Bedreigde Species?, delivered in the University at Leiden, September 9,1988 , and published in pamphlet form by that university.

${ }^{1}$ Methods of Logic, Holt and Co., N.Y. 1950, p. vii.
} 
development of logic could possibly object to the first part of this statement, but I want to take mild exception to the second: logic was great also prior to to the appearance of Frege's Begriffsschrift. ${ }^{2}$ From the perspective I am concerned to develop here, 1837 is as important a year as 1879. In that year Bernhard Bolzano's Wissenschaftslehre made its appearance in four mighty tomes. ${ }^{3}$ The traditional logic that Bolzano rejected can be set out compactly in the following way: 4

\begin{tabular}{|c|c|c|}
\hline Mental operation & (Mental) Product & External Sign \\
\hline Simple Apprehension & $\begin{array}{c}\text { Concept, } \\
\text { Idea, } \\
\text { (Mental) Term }\end{array}$ & $\begin{array}{c}\text { (Written/spoken) } \\
\text { Term }\end{array}$ \\
\hline $\begin{array}{c}\text { Judging, } \\
\text { Composition/Division }\end{array}$ & $\begin{array}{c}\text { Judgement, } \\
\text { (Mental) Proposition }\end{array}$ & $\begin{array}{c}\text { Assertion, } \\
\text { (Written/spoken) } \\
\text { Proposition }\end{array}$ \\
\hline $\begin{array}{c}\text { Reasoning, } \\
\text { Inferring }\end{array}$ & (Mental) Inference & $\begin{array}{c}\text { (Written/spoken) } \\
\text { Inference, } \\
\text { Reasoning }\end{array}$ \\
\hline
\end{tabular}

In particular, traditional logic held that the act of judgement consisted of an act of joining or separating two terms already obtained, the subject and the predicate of the judgement in question, and accordingly the judgement made had the subject/copula/predicate form

\section{$\mathrm{S}$ is $\mathrm{P}$.}

Bolzano replaced this traditional form with the form

$$
\text { truth adheres to the propositional content A, }
$$

and the situation as regards acts of judgements and their products can be set out as follows:

${ }^{2}$ Louis Nebert, Halle, Jena 1879.

3 J. von Seidel, Sulzbach.

${ }^{4}$ The following schema is based on one in J. Maritain, An Introduction to Logic, Sheed \& Ward, London 1946, pp. 6-7. 


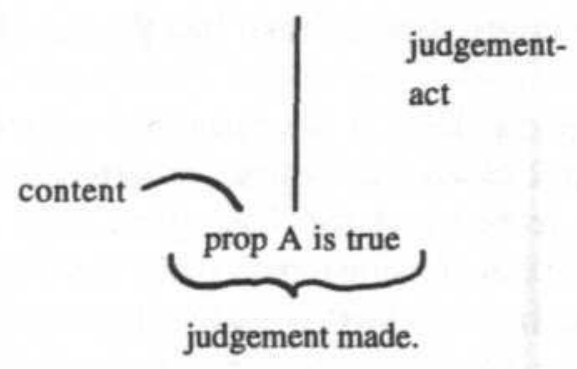

Bolzano was a logical platonist; the propositions that serve as contents of the judgements made were totally an sich, both with respect to their being and their truth or falsity. A Satz an sich is independent of any act of linguistic Setzung or of thought, and the truth of a true proposition is completely independent of any acts of truthmaking. Thus, the act of judgement is valid, and the judgement made is correct, or evident, to speak with Brentano, when the Satz an sich that serves as propositional content of the judgement in question is a truth an sich, rather than vice versa.

Similarly, the validity of an act of inference is reduced to that of a relation of logical consequence between the propositions serving as contents of the premisses and conclusion of the judgement in question. Bolzano nevertheless clearly acknowledged the epistemological role of logic: Urteile and Schlüsse are central notions within the subject, even though their key properties are ultimately reduced to an sich notions.

The work of Frege constitutes no advance over that of Bolzano, as far as the form of judgement

\section{(proposition) $\mathrm{A}$ is true}

is concerned. ${ }^{5}$ It was used also by Frege, probably in complete independence from the earlier work. His 1879 achievement comprises three crucial parts that are of relevance from the present perspective, namely: (i) the invention of the interpreted formal language, the Begriffsschrift, (ii) the insight that the mathematical function/argument structure to analyze the form, not of judgements, but of their propositional contents, and (iii) the use of the special "assertion sign" (not Frege's term, but it

5 Grundgesetze der Arithmetik, Vol I, §2, Jena 1893. 
states just what I want to stress) that brings out the epistemological links of logic.

In all three respects there is a substantial advance as compared to Bolzano. The three points are, of course, interrelated. In particular, the latter two constitute features of the Begriffsschrift in question. Frege quite explicitly emphasizes the epistemological side of logic at the cost of the ontological: the notion of 'fact' is expurgated as being nothing but a true proposition in Der Gedanke and the notion of Sachverhalt does not even occur in his work: if we want to solve the proportion

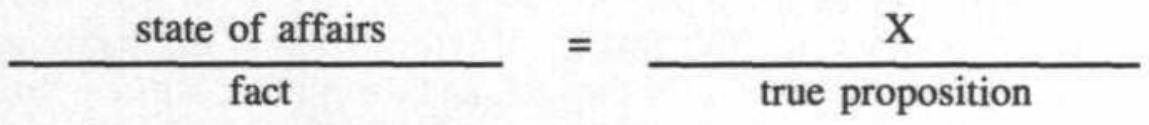

the only solution for $\mathrm{X}$ seems to be proposition. ${ }^{6}$ Furthermore, we should note that Frege leaves truth essentially unanalyzed: according to him it is completely sui generis, or in his terms, 'undefinable'.

The epistemological vision of logic, using an interpreted formal language, as well as an assertion sign, was retained by Russell. ${ }^{7}$ The next step towards a subject-less ontologized conception of logic is perhaps best seen as a response to a certain tension among the basic principles of logic, which was independently felt simultaneously in 1907-8 at Cambridge and in Amsterdam. The tension in question is that between, on the one hand, the law of bivalence, a principle clearly adhered to both by Bolzano and Frege, which states that each proposition is either true or false, independently of whether or not it can be known as such, and, on the other hand, the principle of the knowability of truth. G.E. Moore, in his Aristotelian Society address on 'Professor James' Pragmatism' remarked on the tension and, with the zeal of a renegade idealist, opted for to acknowledge the possibility of unknowable truths. ${ }^{8}$ Indeed, one can only point to potential examples here: an actual, known example of an unknowable truth would represent a contradiction in terms. Indeed, an assertion to the effect that

"P is true, but in principle unknowable."

6 'Der Gedanke', Beiträge zur Philosophie der deutschen Idealismus, 1 (1918-19), pp. 58-77.

${ }^{7}$ A. N. Whitehead and B. Russell, Principia Mathematica, Vol. 1, Cambridge U.P., 1910.

${ }^{8}$ Proc. Arist. Soc., N.S.,V III (1907-8), pp.33-78. 
would be closely akin to Moore's well-known later paradox concerning an assertion made by means of an utterance of the sentence

"It is raining, but I don't believe it."

In Amsterdam, on the other hand, L.E. J. Brouwer, the founder of mathematical intuitionism, naturally opted for the knowability of truth and refrained from affirming the law of bivalence. ${ }^{9}$

The undefinability of truth was challenged early on, in two different ways: first, realistically, by Wittgenstein in the Tractatus and, secondly, idealistically, by Arend Heyting in his proof-theoretical semantics for the intuitionistic logical particles. ${ }^{10}$ Both these challenges constitute variations on the truth-maker version of the correspondence theory of truth. This version is characterized by the reduction principle:

The proposition $\mathrm{A}$ is true

iff

there exists a truth-maker for A. ${ }^{11}$

It is important to stress here that this scheme is completely neutral with respect to the logic that holds for the propositions in question. In particular, the status of the principle of bivalence, which states that every proposition is either true or false, is underdetermined by the scheme and depends essentially on the notions of truth-maker and existence that are employed in the formulation of the truth-maker analysis.

The constructivist truth-maker in Heyting's work is, of course, the proof(-object) of the proposition in question. This alternative, moderate idealist, theory has been considerably elaborated, technically as well as philosophically, by the Swedish logician Per Martin-Löf and will not further be dealt with in the present paper. ${ }^{12}$

9 'Over de onbetrouwbaarheid der logische principes', Tijdschrift voor Wijsbegeerte 2 (1908), pp. 152-158.

${ }^{10}$ L. Wittgenstein, Tractatus Logico-philosophicus, Routledge and Kegan Paul, London, 1922, and A. Heyting, 'Die intuitionistische Grundlegung der Mathematik', Erkenntnis 2 (1931), pp. 106-115.

11 K. Mulligan, P. Simons, and B. Smith, 'Truth-Makers', Philosophy and

Phenomenological Research XLIV (1984), pp. 287-231.

12 See, for example, Intuitionistic Type Theory, Bibliopolis, Naples, 1984. 
Wittgenstein, in contradistinction to Bolzano and Frege and in explicit opposition to the latter, construed his propositions linguistically in a non-platonistic way: a proposition is a sign in use (with meaning). Each (elementary) proposition A presents a certain Sachverhalt (state of affairs) $S_{A}$. In accordance with the scheme above this Sachverhalt serves as truth-maker for the proposition:

The proposition $\mathrm{A}$ is true

iff

the state of affairs $S_{A}$ exists(obtains).

In the Tractatus it is of crucial importance that the existence of states of affairs is a bivalent notion, so that the principle of bivalence for propositions is induced via the truth-maker analysis of propositional truth. In virtue of this truth-maker analysis, also the relation of logical consequence between propositions is explained in terms of the (relative) existence of state of affairs and logic is thus essentially converted into a means for calculating what Sachverhalte obtain under the supposition that certain other Sachverhalte obtain.

Wittgenstein is very hostile to epistemological matters in the Tractatus. In the notorious 4.442 he sharply rejects the use of an assertion sign by Russell and Frege (which use was retained in the constructivist tradition by Heyting). Indeed, his non-platonistic concept of proposition may seem like a vestige of epistemology in his work, but the appearances are misleading: for logic, the central notions are not those of the proposition and its truth, but the state of affairs and its existence, and the latter are certainly just as platonistic as the Bolzanian Sätze an sich and Fregean Gedanken.

The development of the non-euclidean geometries and the ensuing notion of axioms as hypotheses played an important role in the banishment of content from logic. Hilbert, who perfected this view of axiomatization in his work on the Foundations of Geometry, subsequently applied the same type of axiomatization in his metamathematics. Here, however, matters are sharpened considerably in that the mathematical propositions are formalistically construed as metamathematical well-formed formulae, whence they are totally void of content. A metamathematical "expression" is a (meta)mathematical object; it does not express anything, but may itself, just like any other mathematical object be expressed by means of a mathematical 
expression. Nobody would have thought of using contentless formalisms in logic except for Hilbert's programme. By taking the idea seriously that mathematical propositions can be objects of mathematical study, e.g. that they are mathematical objects, and, in fact, even by converting them into the prime examples of mathematical objects, namely (Gödel) numbers, Gödel was able to refute the Hilbert programme. At the same time Tarski effectuated the separation between syntax and semantics (that was already foreshadowed in earlier work where the formation rules for the well-formed formulae have to be given prior to the deduction rules; the rules of meaningfulness must not depend on the rules of truth is the slogan behind all this.). ${ }^{13}$ It should be noted that the truth predicate, as defined by Tarski, is not applicable to mathematical propositions, but to certain (meta)mathematical objects. Applied to natural language, it is as if we were to apply truth primarily, not to propositions, or to meaningful sentences, but to the ink-stains or chalk with which such sentences are written. Another important feature is that Tarski's definition is completely neutral with respect to the properties of truth: they are completely dependent on the logic that is applicable in the meta theory. This view of formalisms, with formal languages without content, and with the ensuing separation of "syntax" and "semantics" is, by now, completely accepted as the official philosophy of logic, and is rarely, if ever, commented upon.

On the semantical level, the earlier tradition from Boole, ${ }^{14}$ and Schröder, ${ }^{15}$ concerning Umfangslogik, which was sharply criticized by Frege and Husserl, ${ }^{16}$ was taken up again , and given prominence, with the contemplation of different universes of discourse, as employed in the semantics of pure predicate logic. This idea can easily be coupled with the earlier idea concerning the use of contentless formalisms and this, in fact, gets done in the model-theoretic transformation of Tarski's original ideas concerning the definition of truth, first given, as far as I know, by Tarski

13 'Der Wahrheitsbegriff in den formalisierten Sprachen', Studia Philosophica 1 (1936), pp.261-405.

${ }^{14}$ The Mathematical Analysis of Logic, reprint, Basil Blackwell, Oxford 1948.

15 Vorlesungen über die Algebra der Logik,Vols. 1-3, reprint Chelsea, N.Y. 1966.

${ }^{16}$ Cf.G. Frege, 'Kritische Beleuchtung einiger Punkte in E. Schröders Vorlesungen über die Algebra der Logik', Archiv für systematische Philosophie, 1 (1895), pp. 433-456. 
and Vaught in $1957 .{ }^{17} \mathrm{Here}$, the truth-maker analysis is relativized to the set-theoretical structure chosen. One is now not interested in the outright truth of a proposition, but in the satisfiability of a wff $\phi$ with respect to the structure $\mathscr{A}$, relative to the variable assignment $\mathbf{s}$. Thus, in the Tarski-Vaught definition, what gets meaning is not the formula $\phi$, which will remain a mathematical object void of semantical content. What is given meaning is the three-place (meta)mathematical relation

\section{$\phi$ is satisfied by $s$ in 9 .}

In virtue of the systematic recursion by which the satisfaction condition is laid down each formula $\phi$, together with the sequence $s$, serves to determine a certain set-theoretical state of affairs $S_{\phi, s}$ with respect to the structure I, such that

\section{$\phi$ is satisfied by s with respect to 2 \\ iff}

$S_{\phi, s}$ obtains in the structure $\mathfrak{A}$.

(The precise shape of the state of affairs depends of the wff chosen and is determined by the recursion clauses.) The principle of bivalence is uniformly accepted for the existence of such states of affairs: a state of affairs either exists or it does not exist. With this reformulation of Tarski's model-theoretic version, its connection to the Tractatus formulation becomes obvious Naturally enough, also the notion of logical consequence between well-formed formulae, which is explained in terms of satisfaction, can be explained in terms of the (relative) obtaining of the corresponding set-theoretical states of affairs regarding the structure $\mathfrak{A}$.

The use of predicate logic mixed with natural language is more than common. One often encounters examples such as

$$
(\forall \mathrm{x})(\mathrm{x} \text { is a man } \rightarrow \mathrm{x} \text { is mortal), }
$$

where, properly speaking, natural language is treated as if it were a formal language and consequently the model-theoretic semantics is applicable. This means that the world is treated as a set-theoretic

17 'Arithmetical Extensions of Relational Systems', Compositio Mathematica 13 (1957), pp.81-102. 
structure, THE REAL WORLD, say, which can serve as a model for the language in question. This procedure then entails that all ontological assumptions on the structures that are current in the Tarskian paradigm get exported onto the world. In particular, the sharpness of all concepts, which have to have clear-cut boundaries, and the unlimited validity of classical logic, are simply built into the semantics used.

I have put matters in this overly explicit way, so as to spell out with maximum clarity what is definitionally involved in an application of Tarskian, model-theoretic, semantics to natural language. Normally, when teaching a course on beginning or intermediate logic, one would not dwell on the fact that the formalisms studied really have no content, or the the validity of a crucial logical principle is something which is simply postulated rather than argued for. This policy of didactic silence means that philosophy students who have been given a dose of first order logic in their first year course, but who have had no further contact with the subject, run the risk of being misled, simply in virtue of the logic they have been taught to use.

One area, where the use of logic thus conceived might be particular pernicious, is that of the philosophy of mind. Here, the mere use of the current logical paradigm with its concomitant referential semantics seems to foist the idea of a world "out there" onto us. In other words, Cartesian dualism is built into the position from the outset, simply owing to the use of a referential semantics for the language, according to which THE REAL WORLD is fixed and ready, sharply delineated in all its aspects and where the answer to every possibly question is already decided. In fact, this view of the world, that is inherited from the semantics, is nothing but, what Williams has dubbed, 'the absolute conception of the world'. ${ }^{18}$ For basically (spät)Wittgensteinian reasons, I would decline a dualistic conception of mind and world, and, most certainly, I do not wish to have it forced upon me in the course of carrying out my professional duties as the holder of a Chair of Logic.

Similarly, the common use of arguments in philosophy will, when these arguments are held to be ultimately formalizable in predicate logic, enforce the view that all philosophical questions have an answer and that nominal terms in philosophical discourse function as objects of reference. The subject matter of the reasoning will be construed according to referential, Tarskian, semantics and will ultimately issue a picture of

${ }^{18}$ In Descartes. The Project of Pure Inquiry, Penguin, Harmondsworth, 1978. 
philosophy as an enormous set-theoretic structure, call it TRUE PHILOSOPHY (which, or so it seems, has to be a substructure of the structure THE REAL WORLD, be it elementary or not), that comprises all possible philosophical theories, set out in just the right way: the positions of philosophy are transformed into set-theoretical states of affairs concerning the structure TRUE PHILOSOPHY and the correctness of a position becomes the existence of the corresponding state of affairs. Propositions are turned into objects of reference in the structure TRUE PHILOSOPHY and there will be an enormous proliferation of entities. Take the proposition E $\infty$ that there are infinitely many primes. It is an element in the domain of TRUE PHILOSOPHY, but also the proposition that the proposition $E_{\infty}$ is true is such an element as is the proposition that the proposition that $\mathrm{E}_{\infty}$ is true is true , and so on. Indeed, the referential links between the structures THE REAL WORLD and TRUE PHILOSOPHY and the respective languages must themselves occur as states of affairs inside the structure REAL WORLD and the languages in questions, as well as the two structures themselves must also be elements of the domain of REAL WORLD. Again, for Wittgensteinian, and this time basically Tractarian, reasons concerning internal relations, these consequences do not appeal to me.

The point of the above two examples is that the logic that is applicable with respect to a passage of natural language should be read off from, but not be read into, the passage in question. The use of a fixed and ready semantical perspective forces the presuppositions of that perspective onto the the matter under discussion. In my opinion the philosophical benefits that result from such a procedure, if such there be, do not in any way outweigh the philosophical problems that emerge. The most clear-cut of these can perhaps be brought out via the following reasoning: the reference relation and other basic features of the structure THE REAL WORLD can be talked about in natural language, but then they have to be states of affairs in that structure, rather than the relations in virtue of which certain states of affairs can be presented by propositions. Those relations can thus be talked about in propositions, which then have to present (other) states of affairs in the structure THE REAL WORLD, which would have to depend on (other) reference relations, and so on ad infinitum. I, for one, have no faith in the upper stages of this regress and, accordingly, I prefer to step off this referential bandwagon before it takes off. As Tarski himself clearly realized, natural language is 
"semantically closed" and knows no metalanguage. The present point was put with particular clarity by Arthur C. Danto:

Let $s$ be a sentence which is about the world. Any such sentence I shall call descriptive. If $s$ is descriptive, and about the world, what shall we say about the sentence 's is true'? The latter, unlike $s$, is about $s$. But it is not wholly about $s$, the way for example, the sentence 's is a sentence' is about $s$. Rather it is about $s$ and the world together. And it tells us something which $s$ does not.It does not tell us anything about the world beyond what $s$ alone tells us. It only tells us that what $s$ says about the world is so. Sentences which are about the relations between the world and sentences, I shall speak of as semantical. Relations within the world find verbal expression in descriptive sentences. Relations between the world and descriptions of the world find verbal expression in semantical sentences. The distinction is absolute and irreducible, quite as the relation between language and the world is not reducible to just another intra-worldly-relation. The world is an external world only in the respect that semantical relations are not intra-worldly. Bad philosophy is always generated by trying to flatten semantical relationships into further bits of the world, and allowing the distinctions we have been drawing to collapse. ${ }^{19}$

The considerations offered above concerning the consequences of the model-theoretic perspective in semantics are, of course, strongly dependent on my personal philosophical taste. Since I myself do not share the realist paradigm with respect to the objectivity and solvability of philosophical problems, it does not shock me to find a reference to personal taste in a philosophical argument. Indeed, I do not expect there to be any knockdown arguments in philosophy. Fichte, in a perceptive discussion of the realist/anti-realist debate, remarked that one could not expect either party ever to convince the other; what you get is a helix of ever more refined positions, each of which tries to take the alleged defects of its predecessor positions into account. ${ }^{20} \mathrm{I}$ am gratified to find myself in agreement on this point with one of the foremost (founder-) exponents of the realist logico-semantical tradition, namely the late Heinrich Scholz, who was fully aware of the strong ontological presuppositions underlying the realist framework he preferred. ${ }^{21} \mathrm{He}$ explicitly endorsed the argument offered in the defence of realism by Bertrand Russell:

\footnotetext{
${ }^{19}$ Analytical Theory of Knowledge, C.U.P., 1968, p. x.

20 'Erste Einleitung in die Wissenschaftslehre', Philosophisches Journal, V (1797),1-47.

${ }^{21}$ Heinrich Scholz $(\dagger)$ and Gisbert Hasenjaeger, Grundzüge der Mathematischen Logik, Springer, Berlin, 1961, Einleitung, pp. 11-12.
} 
My argument for the law of excluded middle and against the definition of 'truth' in terms of 'verifiability' is not that it is impossible to construct a system on this basis, but rather that it is possible to construct a system on the opposite basis, and that this wider system, which embraces unverifiable truths, is necessary for the interpretation of beliefs which none of us, if we are sincere, are prepared to abandon. 22

Scholz concludes his excellent treatment with a moral that is a paraphrase of remark of Fichte's concerning the nature of philosophy:

"Was für eine Logik man wähle, hängt davon ab, was für ein Mensch man is",

and I know of no better moral with which to end the present discussion.

Faculty of Philosophy

22 The Philosophy of Bertrand Russell (third edition), P.A. Schilpp (ed.), Tudor Publ. Co., N.Y., 1951, p. 682. 